\title{
Metabolic Abnormalities in the Hippocampus of Patients with Schizophrenia: A 3D Multivoxel MR Spectroscopic Imaging Study at 3T
}

\author{
(D)E.J. Meyer, (DI.I. Kirov, (D)A. Tal, DM.S. Davitz, (D).S. Babb, DM. Lazar, (DD. Malaspina, and (D) O. Gonen
}

\begin{abstract}
BACKGROUND AND PURPOSE: Schizophrenia is well-known to be associated with hippocampal structural abnormalities. We used 'H-MR spectroscopy to test the hypothesis that these abnormalities are accompanied by NAA deficits, reflecting neuronal dysfunction, in patients compared with healthy controls.
\end{abstract}

MATERIALS AND METHODS: Nineteen patients with schizophrenia (11 men; mean age, $40.6 \pm 10.1$ years; mean disease duration, $19.5 \pm 10.5$ years) and 11 matched healthy controls ( 5 men; mean age, $33.7 \pm 10.1$ years) underwent MR imaging and multivoxel point-resolved spectroscopy (TE/TR, 35/1400 ms) 'H-MRS at 3T to obtain their hippocampal GM absolute NAA, Cr, Cho, and mlns concentrations. Unequal variance $t$ tests and ANCOVA were used to compare patients with controls. Bilateral volumes from manually outlined hippocampal masks were compared by using unequal variance $t$ tests.

RESULTS: Patients' average hippocampal GM Cr concentrations were 19\% higher than that of controls, $8.7 \pm 2.2$ versus $7.4 \pm 1.2 \mathrm{mmol} / \mathrm{L}$ $(P<.05)$; showing no differences, concentrations in NAA were $8.8 \pm 1.6$ versus $8.7 \pm 1.2 \mathrm{mmol} / \mathrm{L}$; in Cho, $2.3 \pm 0.7$ versus $2.1 \pm 0.3 \mathrm{mmol} / \mathrm{L}$; and in mlns, $6.1 \pm 1.5$ versus $5.2 \pm 0.9$ (all $P>.1$ ). There was a positive correlation between mlns and $\mathrm{Cr}$ in patients $(r=0.57, P=.05)$ but not in controls. The mean bilateral hippocampal volume was $\sim 10 \%$ lower in patients: $7.5 \pm 0.9$ versus $8.4 \pm 0.7 \mathrm{~cm}^{3}(P<.05)$.

CONCLUSIONS: These findings suggest that the hippocampal volume deficit in schizophrenia is not due to net loss of neurons, in agreement with histopathology studies but not with prior ${ }^{1} \mathrm{H}-\mathrm{MR}$ spectroscopy reports. Elevated $\mathrm{Cr}$ is consistent with hippocampal hypermetabolism, and its correlation with mlns may also suggest an inflammatory process affecting some cases; these findings may suggest treatment targets and markers to monitor them.

ABBREVIATIONS: $\mathrm{CSI}=$ chemical shift imaging; ${ }^{1} \mathrm{H}-\mathrm{MRSI}=3 \mathrm{D}$ multivoxel ${ }^{1} \mathrm{H}-\mathrm{MRS}$ imaging; $\mathrm{SZ}=$ schizophrenia

S chizophrenia (SZ) is a chronic psychiatric disorder that profoundly alters a person's perception, cognition, and behavior. Due to its high prevalence $(\sim 1 \%)$, early onset, and the limited efficacy of existing treatments, SZ exacts enormous personal and economic tolls. ${ }^{1}$ The characteristic "positive" symptoms of SZ psychosis (delusions, hallucinations, disorganized speech, and

Received March 31, 2016; accepted after revision June 3.

From the Department of Radiology (E.J.M., I.I.K., M.S.D., J.S.B., M.L., O.G.), Center for Advanced Imaging Innovation and Research, Bernard and Irene Schwartz Center for Biomedical Imaging, and Department of Psychiatry (D.M.), Institute for Social and Psychiatric Initiatives, New York University School of Medicine, New York, New York; and Department of Chemical Physics (A.T.), Weizmann Institute of Science, Rehovot, Israel.

This work was supported by National Institutes of Health grants: RC1MH088843, 2K24MH00169, MH108962, EB011639, EB01015, NS081772, NS090417, NS097494; and the Center for Advanced Imaging Innovation and Research (www.cai2r.net), a National Institute of Biomedical Imaging and Bioengineering Biomedical Technology Resource Center (NIH P41 EB017183) and CTSI ULITR000038 (New York University). Assaf Tal acknowledges the support of the Monroy-Marks Career Development Fund, the Carolito Stiftung Fund, the Leona M. and Harry B. Helmsley Charitable Trust, and the historic generosity of the Harold Perlman Family. This research was supported by a research grant from the Sylvia Schaefer Alzheimer's Research Fund. behavior) are accompanied by cognitive decline and "negative" symptoms, including diminished emotional expression and avolition. $^{2}$ Despite recognition as fundamental to the disorder as early as 1919, cognitive and negative symptoms were largely ignored once relatively effective pharmacologic treatments for the positive symptoms emerged in the 1950 s. $^{3}$ In recent years, the development of sophisticated investigative techniques has rekindled interest in the neurobiologic substrate underlying SZ so that therapy may be developed to target the full range of symptoms and alter the clinical course.

This surge of effort has resulted in the development of a plurality of sometimes competing, sometimes overlapping theories of SZ pathophysiology, from the classic neurotransmitter-based theories to genetic-, immune-, synapse-, and network-based the-

\footnotetext{
Please address correspondence to Oded Gonen, PhD, Department of Radiology, New York University School of Medicine, 660 First Ave, 4th Floor, New York, NY 10016; e-mail: oded.gonen@med.nyu.edu

- - Indicates open access to non-subscribers at www.ajnr.org

http://dx.doi.org/10.3174/ajnr.A4886
} 
Table 1: Demographics for controls and patients

\begin{tabular}{|c|c|c|c|c|}
\hline Subject & Status & Age $(y r) / S e x$ & $\begin{array}{c}\text { Disease } \\
\text { Duration (yr) }\end{array}$ & Psychotropic Medication \\
\hline 1 & $\mathrm{C}$ & $45 / M$ & NA & NA \\
\hline 2 & C & $31 / \mathrm{M}$ & NA & NA \\
\hline 3 & C & $29 / F$ & NA & NA \\
\hline 4 & C & $36 / \mathrm{M}$ & NA & NA \\
\hline 5 & $\mathrm{C}$ & $43 / \mathrm{M}$ & NA & NA \\
\hline 6 & $\mathrm{C}$ & $24 / F$ & NA & NA \\
\hline 7 & C & $55 / F$ & NA & NA \\
\hline 8 & C & $26 / F$ & NA & NA \\
\hline 9 & C & $29 / F$ & NA & NA \\
\hline 10 & C & $22 / \mathrm{M}$ & NA & NA \\
\hline 11 & C & $31 / F$ & NA & NA \\
\hline 12 & $P$ & $41 / \mathrm{M}$ & 22 & Fluphenazine \\
\hline 13 & $P$ & $44 / F$ & 27 & Quetiapine \\
\hline 14 & $P$ & $43 / \mathrm{M}$ & 18 & Haloperidol, quetiapine \\
\hline 15 & $P$ & $52 / \mathrm{M}$ & 32 & Citalopram \\
\hline 16 & $P$ & $51 / F$ & 15 & Gabapentin, lithium, ziprasidone \\
\hline 17 & $P$ & $23 / \mathrm{M}$ & 3 & Risperidone \\
\hline 18 & $P$ & $47 / M$ & 31 & $\begin{array}{l}\text { Fluoxetine, risperidone, valproic acid, } \\
\text { trazodone }\end{array}$ \\
\hline 19 & $P$ & $44 / M$ & 26 & Clozapine, valproic acid \\
\hline 20 & $P$ & $26 / M$ & 8 & Ziprasidone \\
\hline 21 & $P$ & $29 / F$ & 8 & Bupropion, aripiprazole, fluphenazine \\
\hline 22 & $P$ & $42 / \mathrm{F}$ & 23 & Ziprasidone, bupropion, eszopiclone \\
\hline 23 & $P$ & $22 / \mathrm{M}$ & 4 & Clozapine \\
\hline 24 & $P$ & $48 / \mathrm{M}$ & 23 & Quetiapine \\
\hline 25 & $P$ & $34 / \mathrm{M}$ & 5 & Risperidone \\
\hline 26 & $P$ & $30 / \mathrm{F}$ & 10 & Risperidone \\
\hline 27 & $P$ & $49 / \mathrm{F}$ & 31 & Aripiprazole \\
\hline 28 & $P$ & $51 / \mathrm{F}$ & 35 & NA \\
\hline 29 & $P$ & $43 / F$ & 20 & Aripiprazole, escitalopram, fluphenazine \\
\hline 30 & $P$ & $52 / \mathrm{M}$ & 30 & $\begin{array}{l}\text { Aripiprazole, valproic acid, hydroxyzine, } \\
\text { paroxetine, trazodone }\end{array}$ \\
\hline
\end{tabular}

Note:-NA indicates not applicable; $\mathrm{C}$, controls; $\mathrm{P}$, patients.

ories. The hippocampus is implicated in many of these theories. $\mathrm{SZ}$ is known to be associated with reduced hippocampal volume, increased basal perfusion, decreased activation during certain memory tasks, decreased neurogenesis in the dentate gyrus, and reduced connectivity with cortical and subcortical regions. ${ }^{4-9} \mathrm{Re}-$ cent findings show that conversion to psychosis in high-risk subjects is predicted by hypermetabolism in the hippocampal CA1 subregion. ${ }^{4}$ Psychosis may be conceptualized as a disruption in learning and memory involving impaired habituation and "runaway" pattern completion due to hippocampal hyperactivity. ${ }^{4,10,11}$ The mechanism underlying these hippocampal abnormalities remains unclear. The absence of gliosis on postmortem histopathology and reduced volume in prodromal and first-episode cases has fomented a shift from neurodegenerative to neurodevelopmental hypotheses. ${ }^{12}$ Lack of classic neurodegeneration with gliosis, however, does not imply the absence of subtler progressive damage and inflammation. Mounting genetic and epidemiologic data suggest a role for aberrant immune function and inflammation in SZ. ${ }^{13}$

${ }^{1} \mathrm{H}-\mathrm{MR}$ spectroscopy measures metabolites used as markers for underlying physiologic processes, most prominently: NAA (NAA and $N$-acetyl aspartylglutamate) for neuronal integrity, $\mathrm{Cr}$ (creatine and phosphocreatine) for energy metabolism, Cho (phosphocholine, choline, and glycerophosphocholine) for membrane turnover, and mIns (myo-inositol) for astroglial proliferation. ${ }^{14}$ Most previous hippocampal ${ }^{1} \mathrm{H}-\mathrm{MR}$ spectroscopy studies in $\mathrm{SZ}$ reported lower $\mathrm{NAA}^{15}$; one found increased $\mathrm{Cr}$ and Cho. ${ }^{15}$ None of 10 others that measured Cho, 7 that measured Cr, or 8 that measured mIns, found changes. ${ }^{16}$ Difficulty interpreting results may stem from diagnostic heterogeneity within and between studies, insufficiently powered samples, and methodologic variation. ${ }^{16}$

This study compares absolute hippocampal GM NAA, Cr, Cho, and mIns levels, obtained with 3D multivoxel ${ }^{1} \mathrm{H}$-MR spectroscopy imaging $\left({ }^{1} \mathrm{H}-\mathrm{MRSI}\right)$ at $3 \mathrm{~T}$, between patients with SZ and controls, to test the hypothesis that patients with SZ have decreased hippocampal GM NAA, reflecting neuronal damage. Higher field strength and ${ }^{1} \mathrm{H}$ MRSI (compared with single-voxel spectroscopy) yield better coverage of the irregular shape of the hippocampus and better SNR and spatial resolution.

\section{MATERIALS AND METHODS Human Subjects}

The patients with SZ or schizoaffective disorders were recruited from the outpatient clinics of New York University Langone Medical Center and Bellevue Hospital, diagnosed on the basis of the Diagnostic Interview for Genetic Studies conducted by clinicians trained for reliability, and had ongoing assessments. ${ }^{17}$ All were taking stable doses of medications and had no other psychiatric or neurologic disorders. Age-matched controls recruited from hospital postings met the criteria of no personal or family history of psychosis, no axis I disorder in the past 2 years, and no known neurologic disorder. Exclusion criteria for both patients and controls included uncontrolled medical illness, MR imaging contraindication or inability to tolerate an MR imaging examination, and substance (except tobacco) use in the past 6 months. Substance use history of the patients was the following: Six of 19 reported current or past tobacco use; 6/19, past cannabis use; $9 / 19$, past cocaine use; and 7/19, past alcohol use. All participant demographics are compiled in Table 1, and all gave institutional review board-approved written consent.

\section{MR Imaging Data Acquisition}

All experiments were performed at $3 \mathrm{~T}$ in a whole-body MR imaging scanner (Magnetom Trio; Siemens, Erlangen Germany) with a transmit-receive head coil (TEM3000; MR Instruments, Minneapolis, Minnesota). For anatomic reference, tissue segmentation, and ${ }^{1} \mathrm{H}$-MRSI VOI guidance, T1-weighted 3D MPRAGE images were obtained from each subject: TE/TI/TR, 2.6/800/1360 ms; matrix, $256 \times 256$; FOV, $256 \times 256 \mathrm{~mm}^{2}$; 160 sections, 1-mm-thick each. These were reformatted into 192 axial, sagittal, and coronal sections at $1-\mathrm{mm}^{3}$ isotropic resolution.

Our noniterative, B0 map-based, BOLERO (B0 Loop-Encoded 

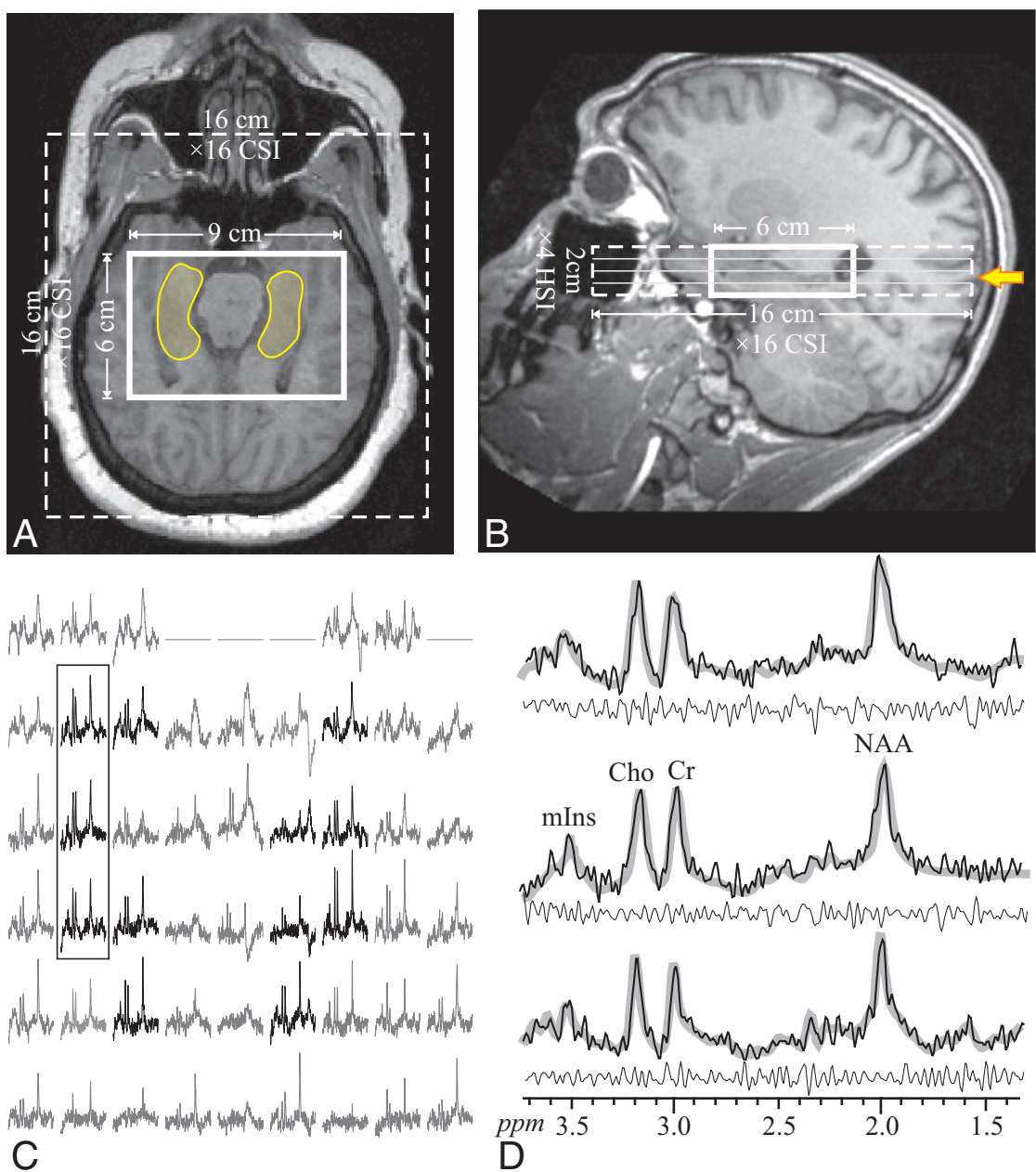

FIG 1. Upper: Axial $(A)$ and sagittal $(B)$ T1-weighted MR imaging from a 23-year-old male patient (17 in Table 1) superimposed on the $9 \times 6 \times 2 \mathrm{~cm}^{3}$ (left-right $\times$ anteroposterior $\times$ inferior-superior) VOI, $16 \times 16 \mathrm{~cm}^{2}$ axial CSI FOV (solid and dashed lines), and the hippocampal outline (transparent yellow on $A$ ). The yellow arrow in $B$ indicates the level of $A, C$, and $D$. Lower left: $C$, Real part of the $9 \times 6$ axial (left-right $\times$ anteroposterior) ${ }^{~} \mathrm{H}$ spectra matrix from the VOI section shown in $A$ and marked with the solid yellow arrow on $B$. Spectra within the hippocampus in $A$ are black, while the remaining ones (not included in the analyses) are gray. All are on a common frequency (parts per million) and intensity scale. The 3 spectra in the black frame over the right hippocampus are expanded on the right $(D)$ for greater detail. Note that the hippocampi do not include voxels at the edges of the VOI (that may have relative VOI chemical shift displacement); note also the good SNR and excellent spectral resolution $\left(8.1 \pm 3.0 \mathrm{~Hz}\right.$ linewidth) from the high spatial resolution $\left(0.5 \mathrm{~cm}^{3}\right)$ voxels. Right: $D$, The 3 spectra from the solid frame on C (black line) overlaid on the spectral fit (thick gray lines) and the residual (experimental - fit) underneath (thin black line). Note the spectral resolution and fidelity of the fit, reflected by the residual.

ReadOut) in-house software adjusted the first- and second-order shims of the scanner to optimize the magnetic field homogeneity over the hippocampi in 3-5 minutes. ${ }^{18} \mathrm{~A} 6-\mathrm{cm}$ anteroposterior $\times$ 9 -cm left-right $\times 2$-cm inferior-superior $=108-\mathrm{cm}^{3}$ parallelepiped ${ }^{1} \mathrm{H}$-MRSI VOI was then image-guided over the bilateral hippocampus, as shown in Fig 1. This VOI was excited by using point-resolved spectroscopy (TE/TR, 35/1400 ms) with 2 secondorder Hadamard-encoded slabs (4 sections) interleaved along the inferior-superior direction at every TR, as shown in Fig $1 B$, for optimal SNR and spatial coverage. ${ }^{19}$ Interleaving also enabled strong, $9 \mathrm{mT} / \mathrm{m}$, Hadamard section-selection gradients, reducing the NAA $\rightarrow$ mIns chemical shift displacement to $\sim 0.13 \mathrm{~mm}, \sim 3 \%$ of the section thickness. ${ }^{20}$ Thin sections were also chosen to reduce broadening from susceptibility gradients in the inferior-su- perior direction from the air-tissue interface with the maxillary sinuses just below, as seen in Fig $1 A$.

The 4 Hadamard section planes were encoded with $16 \times 162 \mathrm{D}$ chemical shift imaging (CSI) over a $16 \times 16 \mathrm{~cm}^{2}$ (leftright $\times$ anteroposterior) FOV to form $1.0 \times 1.0 \times 0.5 \mathrm{~cm}^{3}$ voxels. (Note that the actual voxel size [full width at half maximum of the point spread function] for such uniform 2D phase encoding is $1.12 \times 1.12 \times 0.5=0.63 \mathrm{~cm}^{3},{ }^{21,22}$ because in the Hadamard direction, the nominal equals the actual voxel size $\mathrm{s}^{23}$ ). The VOIs were defined in their planes by two 11.2-ms numerically optimized $180^{\circ}$ radiofrequency pulses $(4.8-\mathrm{kHz}$ bandwidth) under 1.8 and $1.2 \mathrm{mT} / \mathrm{m}$ in the anteroposterior and left-right directions, to yield $9 \times 6 \times 4=216$ voxels (Fig 1C). Such gradients lead the NAA VOI to experience a relative section inplane chemical shift displacement of 2.3 $\mathrm{mm}$ in the anteroposterior and $3.5 \mathrm{~mm}$ in the left-right directions ${ }^{24}$ (ie, of the $6 \times 9 \times 2 \mathrm{~cm}^{3}$ anteroposterior $\times$ leftright $\times$ inferior-superior nominal VOIs, at least $5.7 \times 8.6 \times 2 \mathrm{~cm}^{2}$ [93.4\%] is common for all metabolites). ${ }^{25}$ Note that Cho and $\mathrm{Cr}$ have even smaller relative displacements; the CSI localization grid does not experience this displacement. ${ }^{26}$ Because it is a relative shift, this error is encountered only at the VOI edges, ${ }^{25}$ and it is smaller than the $1 \times 1$ $\mathrm{cm}^{2}$ in-plane CSI resolution. Therefore, to avert it for all metabolites, we chose the in-plane VOI size large enough, $9 \times$ $6 \mathrm{~cm}^{2}$, to have these displacement-error prone voxels at the VOI edges completely outside the hippocampus, as shown in Figs $1 A$ and $2 A$. The MR spectroscopy signals were acquired for 256 ms at $\pm 1-\mathrm{kHz}$ bandwidth. At 2 averages, the ${ }^{1} \mathrm{H}-\mathrm{MR}$ spectroscopy was $\sim 25$ minutes, and the examination took under an hour.

\section{MR Spectroscopy Postprocessing}

The MR spectroscopy data were processed off-line by using inhouse software. Residual water was removed from the MR signals in the time domain ${ }^{27}$; the data was static-field drift-corrected, ${ }^{28}$ voxel-shifted to align the CSI grid with the NAA VOI, Fourier transformed in the temporal, anteroposterior, and left-right directions, and Hadamard reconstructed along the inferior-superior direction. Spectra were automatically corrected for frequency and zero-order phase shifts in reference to the NAA peak in each voxel.

Relative levels of the $i$ th ( $i=$ NAA, Cr, Cho, mIns) metabolite in the $j$ th $(j=1 . .216)$ voxel of the $k$ th $(k=1 . .30)$ subject were 

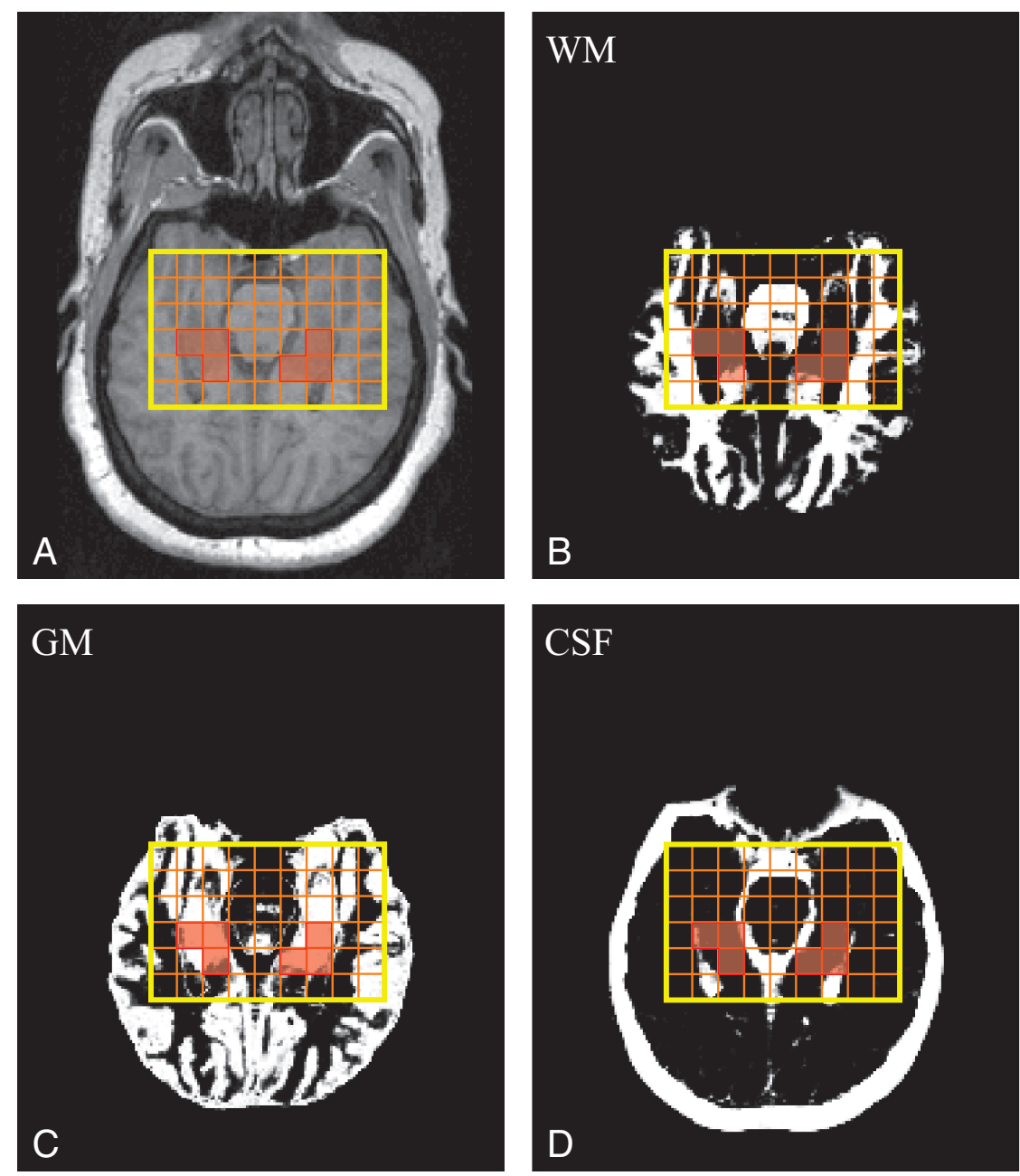

FIG 2. Upper: A, Axial MPRAGE image from a 51-year-old female patient (16 in Table 1) superimposed on the VOI (in yellow). Orange lines show the $9 \times 6$ voxel CSI grid; voxels that passed the selection criteria to calculate the NAA concentration are highlighted in transparent red. $B-D$, SPM12-generated WM (B), GM (C), and CSF (D) masks also superimposed on the VOI CSI grid and selected voxels. Note the $n \geq 2$ voxels that "passed" the selection criteria described in the "Materials and Methods" section.

estimated from their peak area, $S_{\mathrm{ijk}}$, by using parametric spectral modeling, ${ }^{29}$ with Glx, Cho, Cr, mIns, NAA, and taurine model functions, as shown in Fig $1 D$. The $S_{\text {ijk }}$ was scaled into absolute concentration, $C_{\mathrm{ijk}}$, relative to a $2 \mathrm{~L}$ reference sphere of $C_{\mathrm{i}}^{\text {vitro }}=$ $12.5,10.0,3.0$, and $7.5-\mathrm{mmol} / \mathrm{L}$ of NAA, Cr, Cho, and mIns in water at physiologic ionic strength:

$$
C_{\mathrm{ijk}}=C_{\mathrm{i}}^{\mathrm{vitro}} \times \frac{S_{\mathrm{ijk}}}{S_{\mathrm{ijR}}} \times \frac{V_{\mathrm{k}}^{180^{\circ}}}{V_{\mathrm{R}}^{180^{\circ}}} \times \frac{1}{F_{\mathrm{jk}}} \times f_{\mathrm{i}},
$$

where $S_{\mathrm{ijR}}$ is the metabolite signals of the phantom; $V_{\mathrm{k}}{ }^{180^{\circ}}$ and $V_{\mathrm{R}}{ }^{180^{\circ}}$ are subject and reference radiofrequency voltages for nonselective 1 -ms $180^{\circ}$ pulses; and $F_{\mathrm{jk}}$ is the tissue fraction of that voxel, estimated from the WM-, GM-, and CSF-segmented MPRAGE images, as described below. The $f_{\mathrm{i}}$ corrects $C_{\mathrm{ijk}}$ for in vivo $\left(T_{1}^{\text {vivo }}, T_{2}^{\text {vivo }}\right.$ assuming small patient-control differences) and in vitro $\left(T_{1}^{\text {vitro }}, T_{2}^{\text {vitro }}\right)$ relaxation time differences: ${ }^{30}$

$$
f_{\mathrm{i}}=\frac{\exp \left(-T E / T_{2}^{\text {vitro }}\right)}{\exp \left(-T E / T_{2}^{\text {vivo }}\right)} \times \frac{1-\exp \left(-T R / T_{1}^{\text {vitro }}\right)}{1-\exp \left(-T R / T_{1}^{\text {vivo }}\right)}
$$

by using the $T_{1}^{\text {vivo }}=1.4,1.3,1.1$, and 1.2 seconds and $T_{2}^{\text {vivo }}=343,172,248$, and $200 \mathrm{~ms}$ reported for NAA, Cr, Cho, and mIns at $3 \mathrm{~T}^{31-33} ; T_{1}^{\text {vitro }}=605$, 336,235 , and $319 \mathrm{~ms}$ and $T_{2}^{\text {vitro }}=483$, 288,200 , and $233 \mathrm{~ms}$ in the reference phantom.

Bilateral hippocampi masks were manually traced on the axial MPRAGE images on the basis of an MR imaging atlas, ${ }^{34}$ as shown in Fig $1 A$, and visually verified on sagittal and coronal planes. The axial MR images were segmented into CSF and gray and white matter masks by using SPM12 software (http:// www.fil.ion.ucl.ac.uk/spm/software/ spm12), ${ }^{35}$ as shown in Fig $2 B-D$. An in-house program (Matlab 14; MathWorks, Natick, Massachusetts) calculated the fraction of each tissue mask inside each voxel, ${ }^{36}$ from which $F_{\mathrm{jk}}=$ (GM volume + WM volume) / (voxel volume) for Equation 1 was obtained. We retained only voxels with at least $30 \%$ of their volume within the hippocampus mask. To minimize inclusion of degraded signals, we retained only voxels that also had the following: 1) $F_{\mathrm{jk}}>70 \%$ (ie, contained $<30 \%$ of CSF), 2) Cramer-Rao lower bounds of $<20 \%$ for a given metabolite; and 3) $4 \mathrm{~Hz}<$ linewidths $<13 \mathrm{~Hz}$, as shown in Fig 2. The software then estimated the global GM and WM concentrations of each metabolite in the retained $n \geq 2$ hippocampal voxels by using linear regression, as described previously. ${ }^{36}$ This approach overcomes the GM/WM partial volume issue encountered by single-voxel MR spectroscopy. Note that although metabolic gradients are reported along the long axis of the hippocampus ${ }^{37,38}$ and because the entire structure is taken here as a whole and the intrasubject gradients of these metabolites are reported to be quite similar, our average concentration reported here is nevertheless a useful intersubject comparison metric.

\section{Statistical Analyses}

Exact Mann-Whitney and unequal variance $t$ tests were used to compare the groups in terms of age, the volume measure, and each metabolite concentration without adjustment for age and sex. ANOVA was used to compare the groups in terms of the volume and each metabolite concentration adjusted for age and sex. ANOVA for each measure allowed the error variance to differ across subject groups to avoid an assumption of variance equality. $F$ and Levene tests were used to compare the groups in terms of the variance of the volume measure and each metabolite concentration. All tests were conducted at the $5 \%$ significance level. 
Table 2: Means, number of subjects from whom the data was derived (in parentheses), and $P$ values (from unequal variance $t$ tests) of the absolute NAA, Cr, Cho, and mins hippocampal GM concentrations and the volumes of the bilateral hippocampi in controls and patients ${ }^{a}$

\begin{tabular}{lclc}
\hline \multicolumn{1}{c}{ Metabolite } & \multicolumn{1}{c}{ Controls } & \multicolumn{1}{c}{ Patients } & $\boldsymbol{P}$ Value \\
\hline NAA $(\mathrm{mM})$ & $8.7 \pm 1.2(n=11)$ & $8.8 \pm 1.6(n=16)$ & .876 \\
$\mathrm{Cr}(\mathrm{mM})$ & $7.4 \pm 1.2(n=10)^{\mathrm{b}}$ & $8.7 \pm 2.2(n=19)^{\mathrm{b}}$ & $.035^{\mathrm{b}}$ \\
Cho $(\mathrm{mM})$ & $2.1 \pm 0.3(n=10)$ & $2.3 \pm 0.7(n=18)$ & .189 \\
mlns $(\mathrm{mM})$ & $5.2 \pm 0.9(n=10)$ & $6.1 \pm 1.5(n=12)$ & .161 \\
Volume $\left(\mathrm{cm}^{3}\right)$ & $8.4 \pm 0.5(n=11)^{\mathrm{b}}$ & $7.5 \pm 0.9(n=19)^{\mathrm{b}}$ & $.003^{\mathrm{b}}$
\end{tabular}

a Note the elevation of $\mathrm{Cr}$ and the reduction in volume in patients compared with controls.

b Significant difference.

\section{RESULTS}

Nineteen patients and 11 controls were included in the analyses, as shown in Table 1. The groups were not different with respect to age $(P=.119)$. The BOLERO shim procedure yielded metabolite linewidths of $8.1 \pm 3.0 \mathrm{~Hz}$ across all $216 \mathrm{VOI}$ voxels for patients and controls, as shown in Fig 1. The mean number of voxels that passed the selection criteria described above and were used to estimate metabolite concentrations was $10.5 \pm 3.4$ in patients and $14.5 \pm 5.4$ in controls for NAA; $8.3 \pm 3.4$ and $11.3 \pm 4.9$ for Cho; $8.0 \pm 3.5$ and $12.8 \pm 4.4$ for $\mathrm{Cr}$; and $4.8 \pm 1.7$ and $7.0 \pm 3.8$ for mIns. Average hippocampal GM metabolite concentrations and the volumes of the bilateral hippocampi, as shown in Fig 1A, are given in Table 2. Note that because the analysis was performed independently for each metabolite, different numbers of subjects are included for each on the basis of how many had at least 2 voxels that passed the exclusion criteria.

Patients had 19\% $(P<.05)$ higher hippocampal GM Cr levels than controls, even after adjusting for age and sex, as shown in Table 2 and Fig 3. NAA, Cho, and mIns were not significantly different. The variance of the Cho levels was larger in patients than in controls $(P=.05)$ and trended that way for $\operatorname{Cr}(P=.06)$. There was a positive correlation between $\mathrm{mIns}$ and $\mathrm{Cr}$ levels in patients $(r=0.57, P=.05)$ but not in controls $(r=0.42, P=.26)$. Other metabolites were not significantly correlated. Bilateral hippocampal volume was $\sim 10 \%(P<.05)$ lower in patients.

\section{DISCUSSION}

Most surprising, our findings do not support the hypothesis that patients with SZ exhibit decreased hippocampal GM NAA (due to neuronal dysfunction) compared with healthy controls, as generally reported. ${ }^{16}$ They are, however, concordant with neuropathology studies that consistently find reduced hippocampal volume without a net loss of neurons, but with neuronal architectural disarray and molecular alterations (eg, changes in receptor density and deficits in the inhibitory interneurons that compose $10 \%$ of hippocampal neurons). ${ }^{12}$

Our finding of elevated hippocampal GM Cr in SZ may suggest either altered hippocampal energy metabolism or an increased proportion of glial cells. The $\mathrm{Cr}{ }^{1} \mathrm{H}-\mathrm{MR}$ spectroscopy peak is a composite of free creatine and phosphocreatine that interconvert to regenerate adenosine triphosphate, thus acting as a short-term energy "buffer" for the cell. Cr elevation may, therefore, reflect altered energy metabolism, likely hypermetabolism because a more metabolically active cell reasonably requires greater capacity to regenerate adenosine triphosphate (decreased
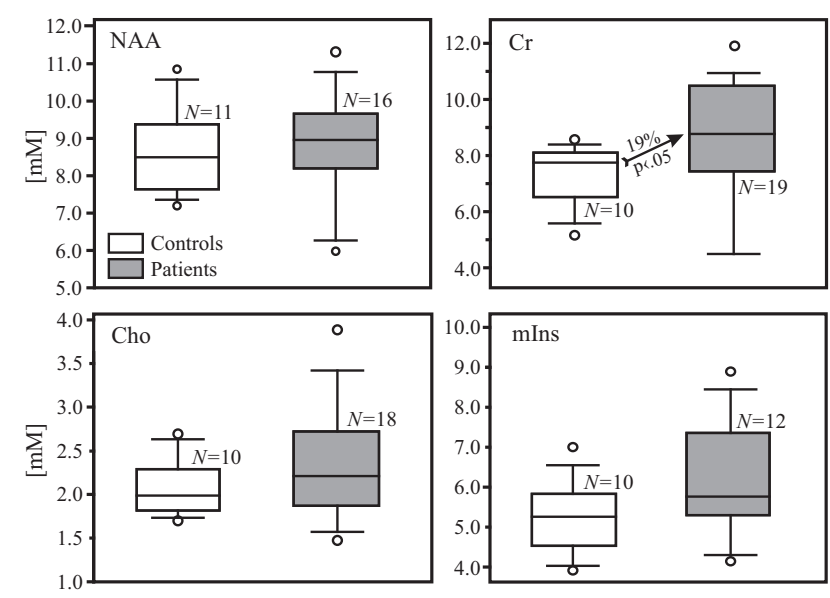

FIG 3. Boxplots showing the first, second (median), and third quartiles; 5th and 95th percentiles (whiskers); and outliers (dots) of the distribution of the bilateral hippocampal NAA, Cr, Cho, and mlns concentrations (millimolar) in the patient (shaded) and control (white) boxes. Numbers of controls and patients included in the analyses for each metabolite, $\mathrm{N}$, are listed. Note that the NAA, Cho, and mlns concentrations do not differ significantly between patients and controls (Table 2), whereas the $\mathrm{Cr}$ concentration is $19 \%$ higher in the bilateral hippocampi of patients than in controls (arrow).

Cr has similarly been interpreted as hypometabolism). ${ }^{10,39} \mathrm{In}$ deed, an increase in energy metabolism is consistent with the hippocampal hyperactivity model of SZ, supported by evidence from animal models, neuroimaging, and histopathology studies. ${ }^{40} \mathrm{Nu}$ clear imaging studies show increased basal perfusion, ${ }^{41}$ which correlates with psychotic symptoms and is normalized by D2 antagonists, ${ }^{42}$ while resting-state fMRI shows hyperactivity correlated with cognitive deficits and negative symptoms. ${ }^{43}$ Hippocampal hyperactivity may be mediated by increased glutamatergic activity, which has been found in the hippocampus of unmedicated patients with SZ and is associated with reduced hippocampal volume and worse executive functioning and global clinical state. ${ }^{44}$ Furthermore, a reciprocal pathway between the hippocampus and dopaminergic neurons in the midbrain supports a link to the dopamine hypothesis of SZ. ${ }^{40}$

Cho and $\mathrm{mIns}$ are elevated alongside $\mathrm{Cr}$ in astrogliosis, reflecting their higher levels in glial cells than neurons. ${ }^{14}$ Although we did not find significant elevations in hippocampal GM Cho or mIns, the correlation between $\mathrm{Cr}$ and mIns in patients (but not controls) suggests that in at least some cases, elevation in Cr may reflect astrogliosis, a response to inflammation. Evidence supporting an immune or inflammatory component in SZ continues to accumulate. This includes the increased risk of SZ after exposure to certain maternal viruses in utero; the increased expression in the hippocampus of genes related to the immune response identified by messenger RNA sequencing; the significant associations with inflammatory-related genes identified in genome-wide association meta-analyses (including in the human leukocyte antigen complex, of which a recent study suggests that increased expression of a complement component gene may mediate excessive synaptic pruning); and the increase in proinflammatory cytokines, including interleukin- 6 and tumor necrosis factor- $\alpha$ in patients with psychosis. ${ }^{45,46}$

That histopathology studies do not show glial cell proliferation in SZ does not rule out the possibility that a subset of patients 
might undergo astrogliosis. ${ }^{12}$ This notion is consistent with the emerging concept of the clinical syndrome of SZ as composed of a group of separate conditions differing in relevant pathophysiologies, termed "SZ and related psychoses." Consistent with the idea of etiologic heterogeneity, patients exhibited greater coefficients of variation than controls for both Cho (28\% versus $16 \%, P=.05$ ) and $\mathrm{Cr}(25 \%$ versus $16 \%, P=.06)$. A subset of patients may undergo an inflammatory process, causing elevated Cho, $\mathrm{Cr}$, and mIns through astrogliosis or subtler inflammation that damages glial cells and/or myelin.

The reduced hippocampal volume seen in patients is consistent with prior reports. Along with the prefrontal cortex, the hippocampus is consistently observed to undergo volume loss in SZ. ${ }^{4}$ A recent collaborative analysis of brain volumes by using imaging data from 2028 individuals with SZ and 2540 healthy controls found the largest patient control effect size for the hippocampus of any subcortical area, with a mean $4.10 \%$ volume decrease compared with controls. ${ }^{47}$ The lack of correlation between hippocampal volume and NAA levels in our study suggests that the lower volume in patients is not due to neuronal loss from progression of a pathogenic process and may, therefore, be suggestive of a developmental trait.

There may be several reasons for the discordance between our findings and most previous studies. First, clinical heterogeneity (disease duration, symptomatology, medications) both between and within studied populations is known to affect ${ }^{1} \mathrm{H}-\mathrm{MR}$ spectroscopy results. ${ }^{16}$ Second, methodology differences are wellknown to affect results. Our 3D technique yields better spatial resolution ( 0.5 versus $3.5 \mathrm{~cm}^{3}$ or larger) and delineation of the irregular shape, with less inclusion of neighboring WM than single voxels, even accounting for partial WM and CSF volume. Third, studies that found lower NAA in patients had, on average, longer TEs, making them more sensitive to quantification errors due to T2-weighting variations, than our short $\mathrm{TE}=35 \mathrm{~ms}$ acquisition. ${ }^{48}$ Fourth, some studies used $\mathrm{Cr}$ as an "internal reference" and reported its ratios with other metabolites. This approach magnifies errors and is further complicated by findings that $\mathrm{Cr}$ is altered in several brain regions in SZ. ${ }^{16}$ Finally, as others have pointed out, there is a publication bias in favor of NAA deficit reports as opposed to a finding of "no change."16

Admittedly, our study also has several limitations. First, our sample comprised patients with varying disease durations, medication regimens, and histories of substance use at insufficient numbers to distinguish the effects of these variables. Second, a relatively small sample size may have limited the power to detect small differences (eg, Cho or mIns elevations in patients). Third, even our improved spatial resolution is insufficient to resolve hippocampal subfields that may be differentially affected in SZ. ${ }^{4}$ Fourth, the regressions used to obtain metabolite concentrations relied on relatively few, 8-14, voxels per individual, because a balance was struck among the 3D ${ }^{1} \mathrm{H}$-MRSI spatial resolution, measurement time, and hippocampal volume. While the number of voxels in the hippocampus may be improved at higher fields, at $3 \mathrm{~T}$, this is likely nearly as good as can be achieved. Fifth, because of the anatomic milieu (deep in the brain, irregularly shaped, near air-filled sinuses), it is difficult to obtain adequate SNR to quantify hippocampal glutamate and glutamine levels. Finally, our in- terpretation of elevated $\mathrm{Cr}$ is limited by the inability of $3 \mathrm{~T}^{1} \mathrm{H}-\mathrm{MR}$ spectroscopy to distinguish $\mathrm{Cr}$ from phosphocreatine resonances, and our proposals of altered energy metabolism and astrogliosis are here supported by inference and existing literature rather than direct measurement.

\section{CONCLUSIONS}

Decreased volume without GM NAA decline in the hippocampus of patients with SZ suggests a process that preserves neuronal integrity and could represent a developmental rather than pathologic disruption. Increased hippocampal GM Cr suggests hypermetabolism and/or possibly astrogliosis in a subset of patients. These findings may have implications for both the pathogenesis and treatment of SZ by supporting the hippocampal hyperactivity model. In some patients, an inflammatory process (possibly involving astrogliosis) may be a treatment target in addition to the antidopaminergic treatments. Indeed, there is growing recognition that the efficacy of antipsychotics may be mediated, in part, through anti-inflammatory action, and there is ongoing effort with promising results for anti-inflammatory agents, including aspirin, COX-2 inhibitors, and $\mathrm{N}$-acetylcysteine as adjuvant therapies. ${ }^{49}$ Therefore, we propose ${ }^{1} \mathrm{H}$-MRSI as both a probe to identify patient subgroups and a method to monitor therapies.

Disclosures: Emma J. Meyer—RELATED: National Institutes of Health.* Ivan I. KirovUNRELATED: Travel/Accommodations/Meeting Expenses Unrelated to Activities Listed: North American Brain Injury Society, Comments: for travel to their annual meeting to give a lecture on proton MR spectroscopy in traumatic brain injury. Mariana Lazar-RELATED: Grant: National Institute of Mental Health, ${ }^{*}$ Comments: This work was funded, in part, by a grant from the National Institute of Mental Health. Dolores Malaspina—RELATED: Grant: National Institute of Mental Health*; UNRELATED: Expert Testimony: Provided "expert opinion" over 10,000 times, Comments: As a psychiatrist, I consult on issues such as psychiatric diagnoses of mass shooters and possible mental illness in transportation agents; Grants/Grants Pending: National Institute of Mental Health. * *Money paid to the institution.

\section{REFERENCES}

1. Wu EQ, Birnbaum HG, Shi L, et al. The economic burden of schizophrenia in the United States in 2002. J Clin Psychiatry 2005;66: 1122-29 CrossRef Medline

2. American Psychiatric Association. American Psychiatric Association. DSM-5 Task Force. Diagnostic and Statistical Manual of Mental Disorders: DSM-5. Washington, DC: American Psychiatric Association; 2013

3. Malaspina D, Walsh-Messinger J, Gaebel W, et al. Negative symptoms, past and present: a historical perspective and moving to DSM-5. Eur Neuropsychopharmacol 2014;24:710-24 CrossRef Medline

4. Tamminga CA, Stan AD, Wagner AD. The hippocampal formation in schizophrenia. Am J Psychiatry 2010;167:1178-93 CrossRef Medline

5. Adriano F, Caltagirone C, Spalletta G. Hippocampal volume reduction in first-episode and chronic schizophrenia: a review and metaanalysis. Neuroscientist 2012;18:180-200 CrossRef Medline

6. Steen RG, Mull C, McClure R, et al. Brain volume in first-episode schizophrenia: systematic review and meta-analysis of magnetic resonance imaging studies. $\mathrm{Br} J$ Psychiatry 2006;188:510-18 CrossRef Medline

7. Iritani S. Neuropathology of schizophrenia: a mini review. Neuropathology 2007;27:604-08 CrossRef Medline

8. Samudra N, Ivleva EI, Hubbard NA, et al. Alterations in hippocampal connectivity across the psychosis dimension. Psychiatry Res 2015;233:148-57 CrossRef Medline 
9. Kirov II, Hardy CJ, Matsuda K, et al. In vivo 7 Tesla imaging of the dentate granule cell layer in schizophrenia. Schizophr Res 2013;147: 362-67 CrossRef Medline

10. Wood SJ, Berger G, Velakoulis D, et al. Proton magnetic resonance spectroscopy in first episode psychosis and ultra-high-risk individuals. Schizophr Bull 2003;29:831-43 CrossRef Medline

11. Schobel SA, Lewandowski NM, Corcoran C, et al. Differential targeting of the CA1 subfield of the hippocampal formation by schizophrenia and related psychotic disorders. Arch Gen Psychiatry 2009; 66:938-46 CrossRef Medline

12. Harrison PJ. The hippocampus in schizophrenia: a review of the neuropathological evidence and its pathophysiological implications. Psychopharmacology (Berl) 2004;174:151-62 Medline

13. Najjar S, Pearlman DM, Alper K, et al. Neuroinflammation and psychiatric illness. J Neuroinflammation 2013;10:43 CrossRef Medline

14. Zhu $\mathrm{H}$, Barker $\mathrm{PB}$. MR spectroscopy and spectroscopic imaging of the brain. Methods Mol Biol 2011;711:203-26 CrossRef Medline

15. Lutkenhoff ES, van Erp TG, Thomas MA, et al. Proton MRS in twin pairs discordant for schizophrenia. Mol Psychiatry 2010;15:308-18 CrossRef Medline

16. Schwerk A, Alves FD, Pouwels PJ, et al. Metabolic alterations associated with schizophrenia: a critical evaluation of proton magnetic resonance spectroscopy studies. J Neurochem 2014;128: 1-87 CrossRef Medline

17. Nurnberger JI Jr, Blehar MC, Kaufmann CA, et al. Diagnostic Interview for Genetic Studies: rationale, unique features, and training. Arch Gen Psychiatry 1994;51:849-59; discussion 863-64 CrossRef Medline

18. Hetherington HP, Chu WJ, Gonen O, et al. Robust fully automated shimming of the human brain for high-field $1 \mathrm{H}$ spectroscopic imaging. Magn Reson Med 2006;56:26-33 CrossRef Medline

19. Goelman G, Liu S, Hess D, et al. Optimizing the efficiency of highfield multivoxel spectroscopic imaging by multiplexing in space and time. Magn Reson Med 2006;56:34-40 CrossRef Medline

20. Goelman G, Liu S, Fleysher R, et al. Chemical-shift artifact reduction in Hadamard-encoded MR spectroscopic imaging at high (3T and 7T) magnetic fields. Magn Reson Med 2007;58:167-73 CrossRef Medline

21. Mareci TH, Brooker HR. Essential considerations for spectral localization using indirect gradient encoding of spatial information. $J$ Magn Reson 1991;92:229-46 CrossRef

22. Brooker HR, Mareci TH, Mao JT. Selective Fourier transform localization. Magn Reson Med 1987;5:417-33 CrossRef Medline

23. Goelman G, Liu S, Gonen O. Reducing voxel bleed in Hadamardencoded MRI and MRS. Magn Reson Med 2006;55:1460-65 CrossRef Medline

24. de Graaf RA. In Vivo NMR Spectroscopy: Principles and Techniques. 2nd ed. Chichester, UK: John Wiley \& Sons; 2007

25. Barker PB, Bizzi A, Stefano ND, et al. Spectral analysis methods, quantitation and common artifacts. In: Clinical MR Spectroscopy Techniques and Applications. Cambridge: Cambridge University Press; 2010:34-50

26. Brown TR, Kincaid BM, Ugurbil K. NMR chemical shift imaging in three dimensions. Proc Natl Acad Sci U S A 1982;79:3523-26 CrossRef Medline

27. Marion D, Ikura M, Bax A. Improved solvent suppression in oneand two-dimensional NMR spectra by convolution of time-domain data. J Magn Reson 1989;84:425-30 CrossRef

28. Tal A, Gonen O. Localization errors in MR spectroscopic imaging due to the drift of the main magnetic field and their correction. Magn Reson Med 2013;70:895-904 CrossRef Medline

29. Soher BJ, Young K, Govindaraju V, et al. Automated spectral analysis III: application to in vivo proton MR spectroscopy and spectroscopic imaging. Magn Reson Med 1998;40:822-31 CrossRef Medline

30. Kirov I, George IC, Jayawickrama N, et al. Longitudinal inter- and intra-individual human brain metabolic quantification over 3 years with proton MR spectroscopy at 3 T. Mag Reson Med 2012;67: 27-33 CrossRef Medline

31. Träber F, Block W, Lamerichs R, et al. $1 \mathrm{H}$ metabolite relaxation times at 3.0 Tesla: measurements of T1 and T2 values in normal brain and determination of regional differences in transverse relaxation. J Magn Reson Imaging 2004;19:537-45 CrossRef Medline

32. Kirov I, Fleysher L, Fleysher R, et al. Age dependence of regional proton metabolites $\mathrm{T} 2$ relaxation times in the human brain at $3 \mathrm{~T}$. Magn Reson Med 2008;60:790-95 CrossRef Medline

33. Posse S, Otazo R, Caprihan A, et al. Proton echo-planar spectroscopic imaging of J-coupled resonances in human brain at 3 and 4 Tesla. Mag Reson Med 2007;58:236-44 CrossRef Medline

34. Oishi K. MRI Atlas of Human White Matter. Amsterdam: Elsevier/ Academic Press; 2011

35. Ashburner J, Friston KJ. Unified segmentation. Neuroimage 2005;26: 839-51 CrossRef Medline

36. Tal A, Kirov I, Grossman RI, et al. The role of gray and white matter segmentation in quantitative proton MR spectroscopic imaging. NMR Biomed 2012;25:1392-400 CrossRef Medline

37. King KG, Glodzik L, Liu S, et al. Anteroposterior hippocampal metabolic heterogeneity: three-dimensional multivoxel proton $1 \mathrm{H}$ MR spectroscopic imaging-initial findings. Radiology 2008;249:242-50 CrossRef Medline

38. Vermathen P, Laxer KD, Matson GB, et al. Hippocampal structures: anteroposterior $\mathrm{N}$-acetylaspartate differences in patients with epilepsy and control subjects as shown with proton MR spectroscopic imaging. Radiology 2000;214:403-10 CrossRef Medline

39. Mazgaj R, Tal A, Goetz R, et al. Hypo-metabolism of the rostral anterior cingulate cortex associated with working memory impairment in $\mathbf{1 8}$ cases of schizophrenia. Brain Imaging Behav 2016;10: 115-23 CrossRef Medline

40. Heckers S, Konradi C. GABAergic mechanisms of hippocampal hyperactivity in schizophrenia. Schizophr Res 2015;167:4-11 CrossRef Medline

41. Malaspina D, Storer S, Furman V, et al. SPECT study of visual fixation in schizophrenia and comparison subjects. Biol Psychiatry 1999;46:89-93 CrossRef Medline

42. Lahti AC, Holcomb HH, Weiler MA, et al. Functional effects of antipsychotic drugs: comparing clozapine with haloperidol. Biol Psychiatry 2003;53:601-08 CrossRef Medline

43. Tregellas JR, Smucny J, Harris JG, et al. Intrinsic hippocampal activity as a biomarker for cognition and symptoms in schizophrenia. Am J Psychiatry 2014;171:549-56 CrossRef Medline

44. Poels EM, Kegeles LS, Kantrowitz JT, et al. Glutamatergic abnormalities in schizophrenia: a review of proton MRS findings. Schizophr Res 2014;152:325-32 CrossRef Medline

45. Sekar A, Bialas AR, de Rivera $\mathrm{H}$, et al. Schizophrenia risk from complex variation of complement component 4. Nature 2016;530: 177-83 CrossRef Medline

46. Hwang Y, Kim J, Shin JY, et al. Gene expression profiling by mRNA sequencing reveals increased expression of immune/inflammation-related genes in the hippocampus of individuals with schizophrenia. Transl Psychiatry 2013;3:e321 CrossRef Medline

47. van Erp TG, Hibar DP, Rasmussen JM, et al. Subcortical brain volume abnormalities in 2028 individuals with schizophrenia and 2540 healthy controls via the ENIGMA consortium. Mol Psychiatry 2016;21:585 CrossRef Medline

48. Bracken BK, Rouse ED, Renshaw PF, et al. T2 relaxation effects on apparent $\mathrm{N}$-acetylaspartate concentration in proton magnetic resonance studies of schizophrenia. Psychiatry Res 2013;213:142-53 CrossRef Medline

49. Sommer IE, van Westrhenen R, Begemann MJ, et al. Efficacy of antiinflammatory agents to improve symptoms in patients with schizophrenia: an update. Schizophr Bull 2014;40:181-91 CrossRef Medline 